\title{
MAGNETIC RESONANCE IMAGING OF THE VERTEBRAL BONY LESIONS AND THEIR TRANSPEDICULAR BIOPSY/FINE NEEDLE ASPIRATION CYTOLOGY CORRELATION
}

\author{
${ }^{1}$ Assistant Professor, Department of Radiodiagnosis, Government Medical College, Kozhikkode. \\ ${ }^{2}$ Senior Resident, Department of Radiodiagnosis, Government Medical College, Kozhikkode. \\ ${ }^{3}$ Professor \& HOD, Department of Radiodiagnosis, Government Medical College, Kozhikkode. \\ ${ }^{4}$ Professor, Department of Radiodiagnosis, Government Medical College, Kozhikkode. \\ 5 Professor , Department of Radiodiagnosis, Government Medical College, Kozhikkode. \\ ${ }^{6}$ Assistant Professor, Department of Radiodiagnosis, Government Medical College, Kozhikkode. \\ ${ }^{7}$ Associate Professor, Department of Radiodiagnosis, Government Medical College, Kozhikkode. \\ ${ }^{8}$ Assistant Professor, Department of Radiodiagnosis, Government Medical College, Kozhikkode.
}

Naufal Perumpalath', Jayesh K. Thambi², V. R. Rajendran'3, P. Rajan', Jineesh ${ }^{5}$, Gomathy Subramnian', Saanida. M. P7, Juvaina P8

\begin{abstract}
The present study was undertaken in department of Radiodiagnosis, Government Medical College, Kozhikkode, Kerala, in 30 patients who underwent MRI scan spine for evaluation of spine pathology. MRI findings were recorded and studied. Transpedicular biopsy or fine needle aspiration cytology of these lesions were done. Histopatological findings were correlated with MRI diagnosis. Sensitivity and specificity of MRI in detection of various spinal lesions were assessed. In this study more numbers of cases was seen above the age of $60 \mathrm{yrs}$, which accounted for $43.3 \%$ of total number of cases. Few cases were seen below the age of 20 years. Infective pathology is more frequent in the middle age and metastatic lesions are more common in the elderly. In our study the metastasis were seen more from adenocarcinoma, which is the most common malignancy that metastasize to vertebrae. Numbers of tuberculosis cases were more in this study, may be due to the higher prevalence rate of tuberculosis in developing countries. Out of the 30 patients selected, number of tuberculosis cases were 11 . MRI showed a positive predictive value of $85.7 \%$. In our study 3 cases of myeloma was suspected in MR Imaging which turned out to be myeloma on histopathology. Number of cases of pyogenic spondylitis was low. Our study showed Positive predictive value of $67 \%$ for these cases. Vertebral lesion are usually diagnosed late in general clinical settings. Imaging plays a major role in identifying these lesions. Transpedicular biopsy under fluoroscopic guidance was extremely useful and had a good yield of positive results.
\end{abstract}

KEYWORDS: Vertebral Lesions, Osteomyelitis, Metastasis, Magnetic Resonance Imaging, Histopathology.

HOW TO CITE THIS ARTICLE: Naufal Perumpalath, Jayesh K. Thambi, V. R. Rajendran, P. Rajan, Jineesh, Gomathy Subramnian, Saanida. M. P, Juvaina P. "Magnetic Resonance Imaging of the Vertebral Bony Lesions and their Transpedicular Biopsy / Fine Needle Aspiration Cytology Correlation”. Journal of Evolution of Medical and Dental Sciences 2015; Vol. 4, Issue 89, November 05; Page: 15392-15396, DOI: $10.14260 /$ jemds/2015/2194.

INTRODUCTION: Diseases of the vertebral spine poses a major problem in health due to the high morbidity caused by it. So early accurate and quick identification of these lesions are at most essential for bringing down the morbidity and mortality. Pyogenic and tuberculous infection of the vertebra like tuberculosis spine, osteomyelitis of spine is frequently seen in many clinical situations.(1) Its localisation, imaging appearance and clinical course are influenced by age, route of infection, virulence of organism, type of organism and other underlying condition like diabetes mellitus and immunosuppression.(2) Neoplastic disease of the spine may arise either as a local lesion developing within or as an extension from adjacent or distal organs. Route of such spread can be haematogenous or lymphatic spread.(3) Metastasis can affect any part of the vertebra and may be the only presenting feature without any signs of the primary lesion. With the development of newer treatment options like highly effective drugs and

Financial or Other, Competing Interest: None.

Submission 15-10-2015, Peer Review 16-10-2015

Acceptance 23-10-2015, Published 03-11-2015.

Corresponding Author:

Dr. Naufal Perumpalath,

Assistant Professor,

Government Medical College,

Kozhikkode.

E-mail: drnaufalp@gmail.com

DOI: 10.14260/jemds/2015/2194. procedures like vertebroplasty and kyphoplasty, early accurate diagnosis of vertebral lesions has become great important. Purpose of this study is to contribute experience in early recognition of vertebral spine lesions, to study the different infective and neoplastic conditions affecting vertebral spine using magnetic resonance imaging (MRI) and to correlate the MRI findings with pathological diagnosis.

\section{MATERIALS AND METHODS:}

Study Design: Diagnostic test evaluation.

Study Setting: Cases referred from various departments to the Department of Radiodiagnosis, Govt Medical College Kozhikode, Kerala, India for MR imaging for strongly suspected lesions of osseous spine.

Study Period: Jan 2013 to Sept 2014.

Sample Size: 30 subjects.

Inclusion Criteria: Patients with symptomatic vertebral spinal conditions.These patients are grouped into infective, neoplastic and other groups.

Exclusion Criteria: Patients with metal implants. Severely debilitated patients. Patients who are medically unfit for invasive procedure.

Study Method: MRI scan of spine was done in our department with 1.5 T MR System (GE SIGNA HDXT). Fluoroscopy guided biopsy/FNAC was done on such patients. 
when indicated, after getting an informed consent from the patient and a relative. The site was decided on the basis of maximum MR findings, least risk patient and radiologist comfort. At every step of their treatment period, data's are collected and tabulated for the statistical conclusion.

Statistical Analysis: SPSS statistical software. P value $<0.05$ $\rightarrow$ statistically significant difference.

\section{RESULT:}

- In case of metastasis MR imaging shows a sensitivity of $80 \%$, specificity of $90 \%$ with a positive predictive value of $80 \%$ and negative predictive value of $90 \%$.

- In case of tuberculosis it has a sensitivity of $100 \%$, specificity of $88.9 \%$, and positive predictive value of $85.7 \%$ and negative predictive value of $100 \%$.

- For myeloma this study shows a sensitivity and specificity of $100 \%$ with positive and negative predictive value of $100 \%$.

- In case of pyogenic spondylitis MR imaging showed a sensitivity of $100 \%$, specificity of $96.4 \%$, and positive predictive value of $67.7 \%$ and negative predictive value of $100 \%$

\section{FNAC/BIOPSY:}

- Transpedicular biopsy was done in all the cases under fluoroscopic guidance using a Murphy's bone biopsy needle under aseptic precaution and local anesthesia.

- A diagnostic yield of $90 \%$ was obtained.

- This shows the high diagnostic utility of transpedicular biopsy under fluoroscopic guidance.

DISCUSSION: Diseases of the vertebral spine poses a major problem in health due to the morbidity caused by it. So it is very important to diagnose vertebral problem at the earliest. With the invention of modern imaging modalities like MRI, vertebral involvement are diagnosed early, but specific diagnosis is still lacking.

This present study is an attempt to correlate the MRI finding of vertebral lesions with histopathological diagnosis. In the study, a MRI diagnosis was obtained initially followed by transpedicular biopsy or fine needle aspiration cytology from the lesion. Histopatological findings are correlated with MRI diagnosis.

In this study more numbers of cases was seen above the age of $60 y r s$, which accounted for $43.3 \%$ of total number of cases. Few cases were seen below the age of 20 years. Infective pathology is more frequent in the middle age and metastatic lesion are more common in the elderly (4). Our study is in accordance with these findings. Infections and neoplasm of the vertebral spine occur in both males and females worldwide, but with a male predominance. In our study also the same observation is obtained $(\mathrm{M}: \mathrm{F}=2: 1)$.

Metastasis to the vertebral column usually occur in the posterior elements due to its red marrow content and high vascularity.(5)
The most common primaries that metastasis to bone in the females are thyroid and breast carcinoma whereas in males it is the lungs and prostate according to series of clinical trials conducted by Drury et al.(6) In our study the metastasis were seen more from adenocarcinoma, which is the most common malignancy that metastasize to vertebrae.

Numbers of tuberculosis cases were more in this study, may be due to the higher prevalence rate of tuberculosis in developing countries.(7) Out of the 30 patients selected, number of tuberculosis cases were 11 . MRI showed a positive predictive value of $85.7 \%$.

Multiple myeloma usually affects the places where marrow is normally active in adults like the vertebral spine, skull, pelvis and rib cage and the area around the shoulder and hips (8). MR imaging is particularly useful for visualizing bone marrow in myeloma patients. In our study 3 cases of myeloma was suspected in MR Imaging which turned out to be myeloma on histopathology.(9)

Number of cases of pyogenic spondylitis was low. It may be due to the wide use of antibiotics.(10) Our study showed positive predictive value of $67 \%$ for these cases. Vertebral lesion are usually diagnosed late in general clinical settings. Imaging plays a major role in identifying these lesions. Transpedicular biopsy under fluoroscopic guidance is extremely useful and had a good yield of positive results.

\section{REFERENCES:}

1. Maiuri F, Ia Conetta G, Gallicehio B et al. Spondylodiscitis - Clinical and Magnetic Resonance Diagnosis. Spine (Philadelphia 1975), 1997; 22: 1741-6.

2. Sharif HS. Role of MR imaging in the management of spinal infections. Am. J.Roentgenol. 1992; 158: 133345.

3. Murphy M D, Andrews C L, Flemming D J, et al: Primary tumours of the spine: Radiologic/ Pathologic correlation. Radiographics. 1996; 16:1131.

4. Kayan I, Syed I, Saifuddin A, et al. Verteberal osteomyelitis without disc involvement. Clin Radiol 2004; 59:881-91.

5. Torma T. Malignant tumours of the spine and the spinal epidural space. A study based on 250 histologically verified cases. Acta Clin. Scand Suppl 225, 1987; 1-138.

6. Drury, AB, Palmer,PH and Highman, WJ: Carcinomatous metastasis to vertebral bodies. J Clin. Pathol. 1964; 17: 448-60.

7. Dagirmanjian A, schils J, MC Henry, et al. MR imaging of vertebral osteomyelitis resited. Am J Roentgenol 1996, 167:1539-43.

8. Erelmann R, Imaging and differential diagnosis of primary bone tumours and tumour like lesions of the spine. Eur J, Radiol 2006; 58: 48-57.

9. Kurugoglu S. Adaletli I, Kanberoglu K. Lumbosacral Osseous tumours in children. Eur J Radiol 2008; 65:257-69.

10. KofferK, strand R, Gebhardt M. percutaneos biopsy of pyogenic infection of the spine in J pediatric ortho 1988; 8:442. 


\begin{tabular}{|c|c|c|}
\hline AGE DISTRIBUTION & FRQUENCY & PERCENTAGE \\
\hline $1-20$ & 2 & 6.7 \\
\hline $21-40$ & 8 & 26.7 \\
\hline $41-60$ & 7 & 23.3 \\
\hline$>61$ & 13 & 43.3 \\
\hline TOTAL & $\mathbf{3 0}$ & $\mathbf{1 0 0}$ \\
\hline Table 1: Frequency distribution of the study group \\
according to age in years \\
\hline
\end{tabular}

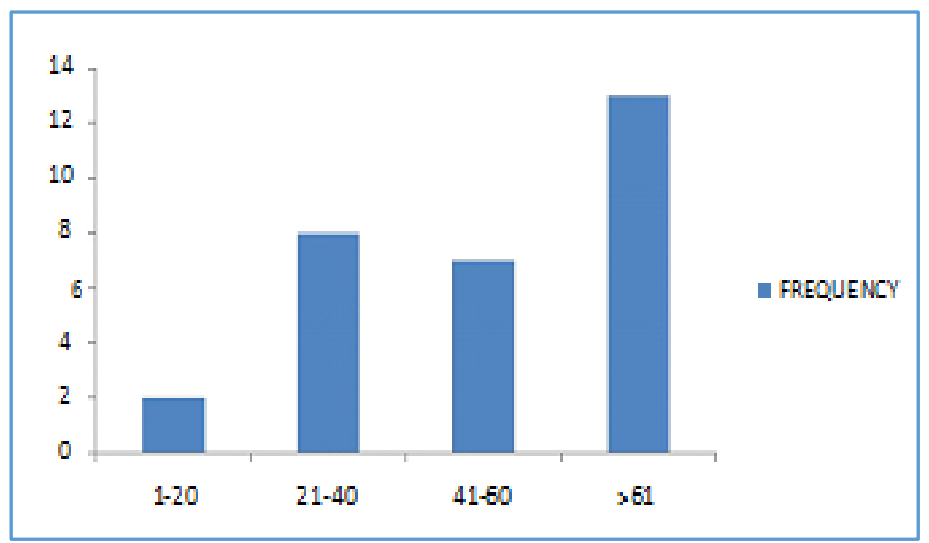

Frequency distribution of the study group according to age in years

\begin{tabular}{|c|c|c|}
\hline MRI DIAGNOSIS & FRQUENCY & PERCENTAGE \\
\hline METASTASIS & 10 & 33.3 \\
\hline TUBERCULOSIS & 14 & 46.7 \\
\hline MYELOMA & 3 & 10 \\
\hline PYOGENIC & 3 & 10 \\
\hline TOTAL & $\mathbf{3 0}$ & $\mathbf{1 0 0}$ \\
\hline \multicolumn{2}{|c|}{ Table 2: Frequency distribution of lesions detected on mri } \\
\hline
\end{tabular}

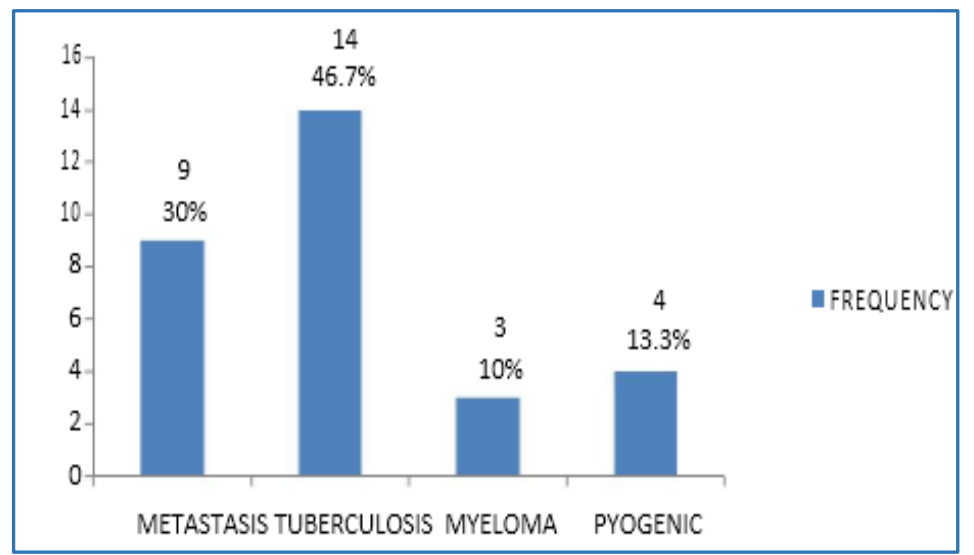

Frequency distribution of lesions detected on mri

\begin{tabular}{|c|c|c|}
\hline HISTOPATHOLOGY & FRQUENCY & PERCENTAGE \\
\hline METASTASIS & 10 & 33.3 \\
\hline TUBERCULOSIS & 12 & 40 \\
\hline MYELOMA & 3 & 10 \\
\hline PYOGENIC & 2 & 6.7 \\
\hline NON SPECIFIC & 3 & 10 \\
\hline TOTAL & 30 & 100 \\
\hline \multicolumn{3}{|c|}{$\begin{array}{c}\text { TABLE 3: Frequency distribution of lesions by } \\
\text { histopathology }\end{array}$} \\
\hline
\end{tabular}




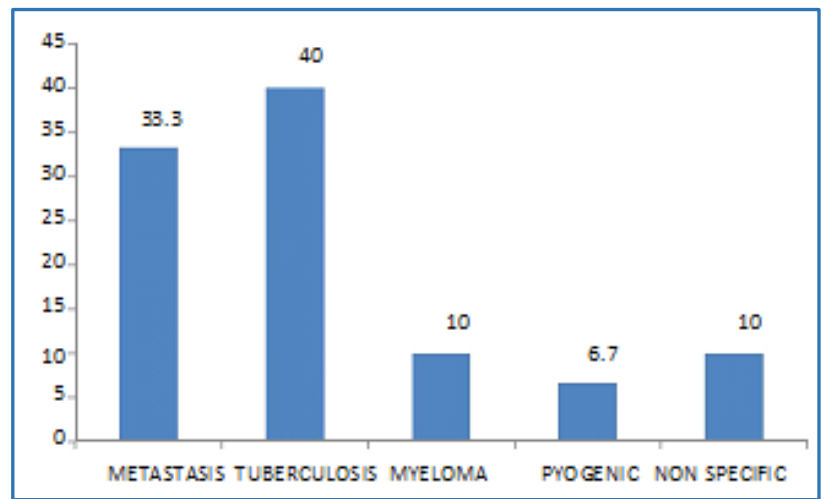

PERCENTAGEDISTRIBUTIONS OF LESIONS BY HISTOPATHOLOGY

\begin{tabular}{|c|c|c|c|c|c|c|}
\hline MRI DIAGNOSIS & 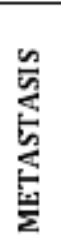 & 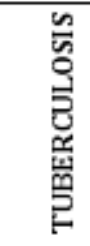 & 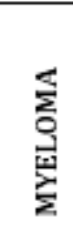 & 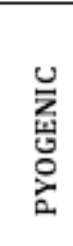 & 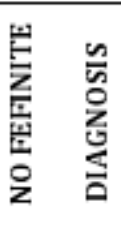 & TOTAL \\
\hline METASTASIS & 8 & 0 & 0 & 0 & 2 & 10 \\
\hline TUBERCULOSIS & 1 & 12 & 0 & 0 & 1 & 14 \\
\hline MYELOMA & 0 & 0 & 3 & 0 & 0 & 3 \\
\hline PYOGENIC & 1 & 0 & 0 & 2 & 0 & 3 \\
\hline TOTAL & 10 & 12 & 3 & 2 & 3 & 30 \\
\hline \multicolumn{7}{|c|}{ Table 4: Distribution of the mri diagnosis against histopathology diagnosis } \\
\hline
\end{tabular}

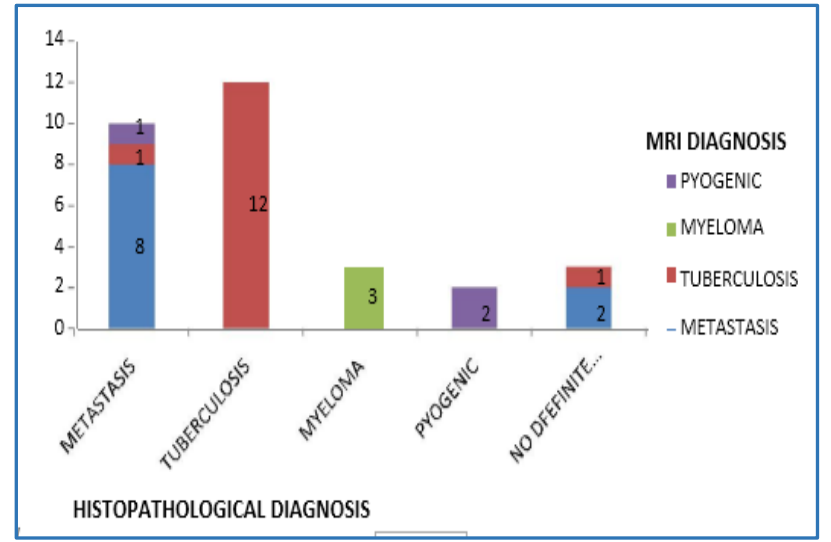

Distribution of the mri diagnosis against histopathology diagnosis EVALUATION OF MRI AS A TEST FOR DIAGNOSIS OF SPINE PATHOLOGY. Metastasis:

\begin{tabular}{|c|c|c|c|c|c|}
\hline \multirow{2}{*}{$\begin{array}{l}\text { MRI DIAGNOSIS AS } \\
\text { METASTASES }\end{array}$} & \multicolumn{4}{|c|}{$\begin{array}{l}\text { METASTASES BY } \\
\text { HISTOPATHOLOGY }\end{array}$} & \multirow[t]{2}{*}{ TOTAL } \\
\hline & POSITIVE & $\%$ & NEGATIVE & $\%$ & \\
\hline POSITIVE & 8 & 26.67 & 2 & 6.67 & 10 \\
\hline NEGATIVE & 2 & 6.67 & 18 & 60 & 20 \\
\hline TOTAL & 10 & & 20 & & 30 \\
\hline \multicolumn{3}{|c|}{ Sensitivity } & \multicolumn{3}{|c|}{$80 \%$} \\
\hline \multicolumn{3}{|c|}{ Specificity } & \multicolumn{3}{|c|}{$90 \%$} \\
\hline \multicolumn{3}{|c|}{ Predictive value of a positive test } & \multicolumn{3}{|c|}{$80 \%$} \\
\hline \multicolumn{3}{|c|}{ Predictive value of a negative test } & \multicolumn{3}{|c|}{$90 \%$} \\
\hline \multicolumn{6}{|c|}{$\begin{array}{c}\text { TABLE 5:COMPARISON BETWEEN MR IMAGING DIAGNOSIS AND } \\
\text { HISTOPATHOLOGICAL DIAGNOSIS OF METASTASES }\end{array}$} \\
\hline
\end{tabular}


Tuberculosis:

\begin{tabular}{|c|c|c|c|c|c|}
\hline \multirow{2}{*}{$\begin{array}{l}\text { MRI DIAGNOSIS AS } \\
\text { TUBERCULOSIS }\end{array}$} & \multicolumn{4}{|c|}{$\begin{array}{l}\text { TUBERCULOSIS BY } \\
\text { HISTOPATHOLOGY }\end{array}$} & \multirow{2}{*}{ TOTAL } \\
\hline & POSITIVE & $\%$ & NEGATIVE & $\%$ & \\
\hline POSITIVE & 12 & 40 & 2 & 6.67 & 14 \\
\hline NEGATIVE & 0 & - & 16 & 53.3 & 16 \\
\hline TOTAL & 12 & & 18 & & 30 \\
\hline \multicolumn{3}{|c|}{ Sensitivity } & \multicolumn{3}{|c|}{$100 \%$} \\
\hline \multicolumn{2}{|c|}{ Specificity } & & \multicolumn{3}{|c|}{$88.9 \%$} \\
\hline \multicolumn{2}{|c|}{ Predictive value of a positive test } & & \multicolumn{3}{|c|}{$85.7 \%$} \\
\hline \multicolumn{2}{|c|}{ Predictive value of a negative test } & & \multicolumn{3}{|c|}{$100 \%$} \\
\hline
\end{tabular}

Myeloma:

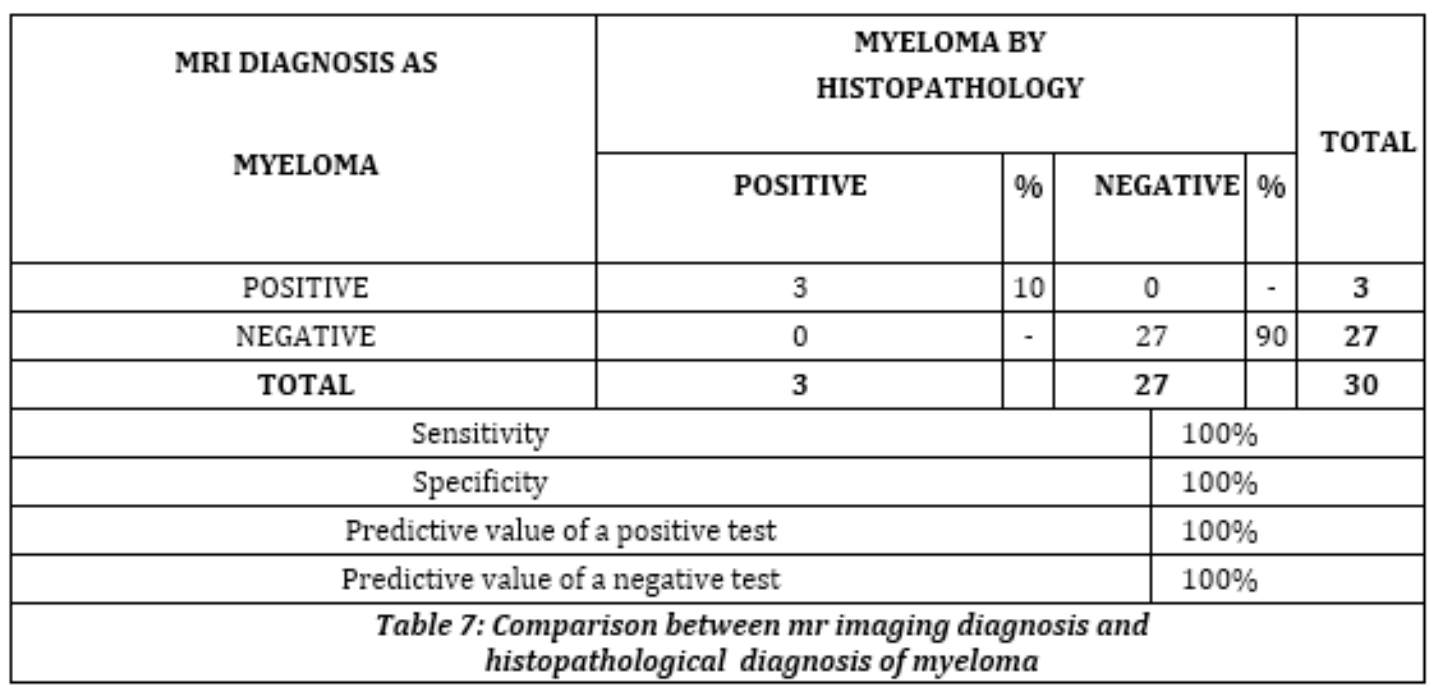

Infective:

\begin{tabular}{|c|c|c|c|c|c|}
\hline \multirow{2}{*}{$\begin{array}{l}\text { MRI DIAGNOSIS AS } \\
\text { PYOGENIC } \\
\text { SPONDYLITIS }\end{array}$} & \multicolumn{4}{|c|}{$\begin{array}{l}\text { PYOGENIC SPONDYLITIS BY } \\
\text { HISTOPATHOLOGY }\end{array}$} & \multirow{2}{*}{ TOTAL } \\
\hline & POSITIVE & $\%$ & NEGATIVE & $\%$ & \\
\hline POSITIVE & 2 & 6.67 & 1 & 3.33 & 3 \\
\hline NEGATIVE & 0 & - & 27 & 90 & 27 \\
\hline TOTAL & 2 & & 28 & & 30 \\
\hline \multicolumn{4}{|c|}{ Sensitivity } & \multicolumn{2}{|l|}{$100 \%$} \\
\hline \multicolumn{3}{|c|}{ Specificity } & \multicolumn{3}{|c|}{$96.4 \%$} \\
\hline \multicolumn{3}{|c|}{ Predictive value of a positive test } & \multicolumn{3}{|c|}{$66.7 \%$} \\
\hline \multicolumn{3}{|c|}{ Predictive value of a negative test } & \multicolumn{3}{|c|}{$100 \%$} \\
\hline \multicolumn{5}{|c|}{$\begin{array}{c}\text { Table 8: Comparison between mr imaging diagnosis and } \\
\text { histopathological diagnosis of pyogenic spondylitis }\end{array}$} & \\
\hline
\end{tabular}

